\title{
Management of Asthma Exacerbations in Southeast Asian Tertiary Care
}

\author{
Mau-Ern Poh (1D) \\ Sundari Ampikaipakan ${ }^{2}$ \\ Chong-Kin Liam (1D) \\ Chee-Shee Chai $\mathbb{D I}^{3}$ \\ Deventhari Ramanaidoo' \\ Helmy Haja Mydin² \\ 'Department of Medicine, Faculty of \\ Medicine, University of Malaya, Kuala \\ Lumpur, Malaysia; ${ }^{2}$ The Lung Centre, \\ Pantai Hospital Kuala Lumpur, Kuala \\ Lumpur, Malaysia; ${ }^{3}$ Department of \\ Medicine, Faculty of Medicine, University \\ Malaysia Sarawak, Sarawak, Malaysia
}

Correspondence: Mau-Ern Poh

Department of Medicine, Faculty of

Medicine, University of Malaya, Kuala

Lumpur, 50603, Malaysia

Tel +603-79494422

Email ernestpoh@gmail.com
Background: There have been limited reports looking into the care of patients with asthma exacerbations admitted to tertiary hospitals in Southeast Asia. This study aims to determine the extent in which the 2019 Global Initiative for Asthma (GINA) guidelines were being met. Methods: A retrospective study of patients with asthma exacerbations admitted to the University of Malaya Medical Centre (UMMC) and Pantai Hospital Kuala Lumpur (PHKL), Malaysia from 1 July 2019 to 31 December 2019.

Results: There were significant numbers of patients with previous admissions for asthma in both centres, with almost $50 \%$ experiencing an exacerbation in the previous year. Approximately $75 \%$ of the patients considered their asthma to be controlled when asked, despite many of them having had a history of acute exacerbations in the previous year. When cross-checked, the level of GINA-defined asthma control remained low, with only $6.4 \%$ of the patients deemed to have good control, while asthma was partially controlled in $25.6 \%$ of the patients and uncontrolled in $68 \%$ of the patients. About $72.1 \%$ of the patients reported daytime symptoms, $65.1 \%$ of the patients reported night-time symptoms, $70.9 \%$ of the patients required frequent usage of rescue inhalers and $72.1 \%$ of the patients reported some limitation in their activity prior to the current asthma exacerbation. Almost a quarter of the patients who were admitted had severe or life-threatening exacerbations as defined by GINA. These patients had more hospitalizations in a year and were more likely to have previous admissions requiring non-invasive and invasive ventilation. They were also more likely to be on GINA Step 5 treatment, had a lower mean percent predicted $\mathrm{FEV}_{1}$ and a higher baseline blood eosinophil count. Multivariate analysis revealed that baseline eosinophil count were independently associated with severe or life-threatening asthma exacerbations (odds ratio: $1.01,95 \%$ confidence interval: $1.00-1.01, \mathrm{p}=0.001$ ). Failure to adhere to daily controller medications was high in this study (37.2\%).

Conclusion: Although the management of asthma exacerbations in tertiary hospitals in Southeast Asia is largely congruous with international guidelines, there is room for improvement. As there is a marked discrepancy between patient-perceived and guideline-defined asthma control, efforts to increase awareness on the dangers of uncontrolled asthma are warranted.

Keywords: acute care, Southeast Asia, severe asthma, international guidelines, management

\section{Introduction}

Asthma is defined by the presence of respiratory symptoms such as wheeze, shortness of breath, chest tightness and cough, together with variable expiratory airflow limitation. ${ }^{1}$ It is one of the most common chronic conditions in the world, affecting approximately 339 million people worldwide. ${ }^{2}$ In 2015, the Global Burden of Disease collaboration found asthma to be the most prevalent chronic respiratory 
disease worldwide, with an estimate of 400,000 deaths from asthma, which was more than 1000 deaths per day. ${ }^{3}$ The global prevalence of asthma is projected to increase to more than 400 million by 2025, partly due to a large proportion of the world's population living in urban areas by then. ${ }^{4}$ In Southeast Asia, asthma is one of the common non-communicable diseases. ${ }^{5}$ Although asthma often begins in childhood, asthma symptoms can occur at any time in life with some patients having late-onset asthma experiencing symptoms for the first time at a later stage in life. ${ }^{6-8}$

Sadly, asthma control remains suboptimal despite the availability of effective controller medications. ${ }^{9,10}$ Poor asthma control is associated with increased risk of exacerbations, impaired quality of life, increased health-care utilisation and reduced productivity. ${ }^{9-12}$ More importantly, a history of asthma exacerbations is a risk factor for future exacerbation; therefore, understanding risk factors is important. Other risk factors for asthma exacerbations include comorbidities such as allergic rhinitis, chronic rhinosinusitis and obesity, poor asthma control and poor treatment adherence. ${ }^{13,14}$

Many countries have formulated and published their own asthma management guidelines to improve overall asthma care. Despite the availability of international guidelines such as those produced by the Global Initiative for Asthma (GINA), awareness towards acute asthma management may be lacking and real-world data are therefore necessary to look at differing management with the aim of improving the standard of care in individual countries based on local practices. The GINA guidelines are well known in the region and the real-world practice of managing asthma exacerbations was assessed using the 2019 version as a reference. ${ }^{2}$

This study aimed to evaluate the quality of care of patients who presented to the emergency departments of two tertiary care centres in Southeast Asia for acute asthma exacerbations. The quality of care evaluated included the initial assessment, management of the exacerbation and discharge arrangements, in an attempt to compare real-world practice with other developing countries in Asia, with the hope of finding concepts that may be generalizable to the rest of the world. The study assessed symptoms and levels of asthma control in a real-life setting, and evaluated how symptoms and the severity of acute exacerbations relate to GINA-defined control and different treatment levels.

\section{Methods}

This retrospective study included all adult patients admitted to University of Malaya Medical Centre (UMMC) and Pantai Hospital Kuala Lumpur (PHKL) for acute asthma during the period from 1 July 2019 to 31 December 2019. For patients with recurrent admissions, only the first admission for asthma exacerbation during the study period was analysed.

A patient with asthma was defined by having a history of respiratory symptoms such as wheeze, shortness of breath, chest tightness and cough that vary over time and in intensity, together with documentation of expiratory airflow limitation by spirometry with bronchodilator reversibility testing. ${ }^{1}$

All adults aged 18 years and above with a prior documented diagnosis of asthma by a physician were eligible for inclusion. Patients without a prior objective spirometry demonstrating reversible expiratory airflow limitation were included if they had the diagnosis confirmed by spirometry testing upon discharge or on follow-up in the outpatient clinic. Patients with newly diagnosed asthma who first presented with an acute exacerbation were also included provided the diagnosis was confirmed in a similar manner. Patients who did not fulfil these criteria were excluded. Informed consent was obtained from all participants prior to data capturing to publish the information gathered in an online open-access publication.

An acute exacerbation of bronchial asthma (AEBA) was an acute or sub-acute worsening in symptoms of shortness of breath, cough, wheezing or chest tightness and progressive decline in lung function, representing a change in the patient's usual status that is sufficient to require a change in treatment. ${ }^{1}$ Some patients may present for the first time during an acute exacerbation. ${ }^{1}$ Based on severity, the exacerbations were categorised as "moderate" or "severe-to-life-threatening" for analysis. A moderate exacerbation is characterized by a patient who was able to talk in phrases, preferred sitting to lying, appeared not agitated, was not using accessory respiratory muscles, and with an increased respiratory rate, a pulse rate of between 100 and 120 beats per minute, an oxygen saturation of $90-95 \%$ on air, and a peak expiratory flow of more than $50 \%$ predicted. ${ }^{1}$ A severe-to-life-threatening exacerbation was characterized by a patient who was only able to talk in words, sitting hunched forwards, agitated and using accessory respiratory muscles, with a respiratory rate of more than 
30 breaths per minute, a pulse rate of more than 120 beats per minute, an oxygen saturation of less than $90 \%$ on air and a peak expiratory flow of $50 \%$ or less of predicted value; or appeared drowsy, confused with a silent chest. ${ }^{1}$

The data capture form included assessing asthma control according to the GINA guidelines over a period of 12 weeks during a steady state prior to the exacerbation requiring hospital admission. ${ }^{1}$ The level of asthma control was defined by daytime symptoms, normal activities affected by symptoms, night-time awakenings and reliever inhaler use. ${ }^{1}$ Patients were also characterized by the treatment step that they were placed under prior to the exacerbation according to GINA 2019 guidelines, namely Step 1 to Step 5. ${ }^{1}$ Smoking status were defined by the Centers for Disease Control and Prevention (CDC), 2017. ${ }^{15}$ A patient was deemed adherent to treatment if from history, they adhered with daily controller medications as recommended by GINA according to the preferred controller medications for Step 2 to Step 5.

The assessment was carried out with the performance indicators set based on the management of asthma exacerbations in the acute care setting found in the 2019 GINA guidelines. These included

1. Assessment of severity from the history, degree of dyspnoea, respiratory rate, pulse rate, oxygen saturation and lung function, while starting shortacting beta ${ }_{2}$-agonist (SABA) and oxygen therapy.

2. Arrangement for immediate transfer to intensive care if the patient was drowsy, confused, or had a silent chest.

3. Starting treatment with repeated administration of SABA, early introduction of oral corticosteroids, and controlled flow oxygen.

4. Review of response of symptoms, oxygen saturation and lung function after 1 hour. Consideration of intravenous magnesium sulfate for patients with severe exacerbations not responding to initial treatment.

5. Arrangement for ongoing treatment before the patient was discharged home. This should include starting controller treatment or stepping up the dose of the existing controller treatment for 2-4 weeks and reducing reliever medication to as-needed use.

6. Arrangement for a follow-up appointment within 1 week of discharge. This should include addressing medications, inhaler skills and written asthma action plan.
Descriptive analysis was performed on participants' sociodemographic details and asthma-related variables. These values are presented as mean \pm standard deviation (SD) or median (range) for continuous variables and frequency (percentage) for categorical variables. Initial data entry was cross-checked by two independent individuals to ensure correct data entry. Before each analysis, data were again checked for consistency. All computations and statistical analyses were performed using statistical SPSS software (Statistical Package for the Social Sciences) programme version 25 (Chicago, IL, USA). Univariate and multivariate analyses were performed comparing patients with "moderate" exacerbations with "severe-to-lifethreatening" exacerbations as defined by GINA 2019.

Differences between groups were tested for significance with the Pearson chi-square test or Fisher's exact test whichever was appropriate for categorical variables and Student's $t$-test for continuous variables. A two-sided $\mathrm{p}$ value of less than 0.05 was considered statistically significant.

The result of multivariate analysis using binary logistic regression is reported as odds ratio (OR) with $95 \%$ confidence intervals (CI) and $\mathrm{p}$ value.

The study was approved and granted ethical clearance by the medical ethics review board of University of Malaya Medical Centre (MECID No: 2018725-6524). All experimental protocols involving human data in the study were in accordance with guidelines from the Declaration of Helsinki.

\section{Results}

\section{Sociodemographic and Clinical Characteristics of Patient}

Table 1 shows the sociodemographic characteristics of patients according to the severity of their asthma exacerbations. A total of 172 patients were admitted for acute asthma exacerbation during the study period. Of these, $75.6 \%$ of the patients had a moderate exacerbation while the remaining $24.4 \%$ had a severe or life-threatening exacerbation. There was a female preponderance (67.4\%). Moreover, $46.6 \%$ of the patients were of Malay ethnicity, $36 \%$ were Indian, $11.6 \%$ were Chinese and the remainder $5.8 \%$ were from other native groups of the states of Sabah and Sarawak. Approximately $10.5 \%$ of the patients were current smokers and $6.4 \%$ were former-smokers. Comparing patients with moderate exacerbation versus those with severe or lifethreatening exacerbation, there were no differences in terms 
Table I Sociodemographic Characteristics of Patients According to Severity of Exacerbations

\begin{tabular}{|c|c|c|c|c|}
\hline Characteristics & $\begin{array}{l}\text { Total Patients } \\
\qquad \mathrm{N}=172\end{array}$ & $\begin{array}{c}\text { Patients with } \\
\text { Moderate AEBA } \\
n=130\end{array}$ & $\begin{array}{l}\text { Patients with Severe or Life- } \\
\text { Threatening AEBA } \\
n=42\end{array}$ & $\begin{array}{l}\text { p-value } \\
\text { of Univariate } \\
\text { Analysis }\end{array}$ \\
\hline \multicolumn{5}{|l|}{ Gender, n (\%) } \\
\hline Male & $56(32.6)$ & $39(30.0)$ & $17(40.5)$ & 0.208 \\
\hline Female & $116(67.4)$ & $91(70.0)$ & $25(59.5)$ & \\
\hline Age, mean \pm SD (years) & $50.3 \pm 19.3$ & $50.0 \pm 18.5$ & $51.1 \pm 21.8$ & 0.761 \\
\hline \multicolumn{5}{|l|}{ Ethnicity, n (\%) } \\
\hline Malay & $80(46.6)$ & $55(42.3)$ & $25(59.5)$ & 0.267 \\
\hline Indian & $62(36.0)$ & $50(38.5)$ & $12(28.6)$ & \\
\hline Chinese & $20(11.6)$ & $17(13.1)$ & $3(7.1)$ & \\
\hline Others & $10(5.8)$ & $8(6.2)$ & $2(4.8)$ & \\
\hline \multicolumn{5}{|l|}{ Smoking status, $\mathbf{n}(\%)$} \\
\hline Never smoker & $143(83.1)$ & III (85.4) & $32(76.2)$ & 0.107 \\
\hline Current smoker & $18(10.5 \%)$ & $10(7.7)$ & $8(19.0)$ & \\
\hline Former smoker & II (6.4\%) & $9(6.9)$ & $2(4.8)$ & \\
\hline $\begin{array}{l}\text { Age of onset, mean } \pm \text { SD } \\
\text { (years) }\end{array}$ & $20.9 \pm 17.8$ & $21.2 \pm 17.4$ & $19.8 \pm 18.9$ & 0.660 \\
\hline \multicolumn{5}{|l|}{ Childhood asthma, n (\%) } \\
\hline Yes & $93(54.1)$ & $67(5 \mathrm{I} .5)$ & $26(61.9)$ & $0.24 I$ \\
\hline No & 79 (45.9) & $63(48.5)$ & $16(38.1)$ & \\
\hline \multicolumn{5}{|l|}{$\begin{array}{l}\text { Family history of } \\
\text { asthma, } \mathrm{n}(\%)\end{array}$} \\
\hline Yes & $96(55.8)$ & $69(53.1)$ & $27(64.3)$ & 0.203 \\
\hline No & $76(44.2)$ & $61(46.9)$ & $15(35.7)$ & \\
\hline \multicolumn{5}{|l|}{ Atopy, n (\%) } \\
\hline No & $120(69.8)$ & $97(74.6)$ & $23(54.8)$ & 0.015 \\
\hline Yes & $52(30.2)$ & $33(25.4)$ & $19(45.2)$ & Multivariate: 0.096 \\
\hline \multicolumn{5}{|l|}{ Co-morbidities, n (\%) * } \\
\hline No & $63(36.6)$ & $52(40.0)$ & II (26.2) & 0.106 \\
\hline Yes & $109(63.4)$ & $78(60.0)$ & $31(73.8)$ & \\
\hline
\end{tabular}

Note: *List of comorbidities are shown in the supplementary table SI.

Abbreviation: AEBA, acute exacerbation of bronchial asthma.

of gender, age group, age of onset, ethnicity, presence of childhood asthma, family history of asthma and presence of comorbidities. Patients with severe or life-threatening exacerbation were significantly more likely to have a history of atopy $(\mathrm{p}=0.015)$.

Table 2 shows important clinical characteristics of patients pertaining to their asthma control when classified according to the severity of their current exacerbation. Based on the GINA definition for asthma control, only $6.4 \%$ of the patients were deemed to have good control of their asthma while asthma was partially controlled in $25.6 \%$ and uncontrolled in $68 \%$.
There were significant numbers of patients with previous admissions for asthma in both centres with an average of 3.9 admissions per patient in their lifetime. About $49.4 \%$ of the patients reported at least one exacerbation in the previous year. The severity of the current exacerbation was determined by previous admissions for asthma. Patients with an exacerbation in the previous year were significantly more likely to present with a severe or lifethreatening exacerbation $(p=0.01)$. This group of patients also had significantly more hospitalizations in a year with an average of 2.8 admissions versus 1.8 admissions $(p<0.001)$. They were also significantly more likely to 
Table 2 Clinical Characteristics of Patients Prior to Asthma Exacerbation

\begin{tabular}{|c|c|c|c|c|c|}
\hline Characteristics & $\begin{array}{c}\text { Total } \\
\text { Patients } \\
N=172\end{array}$ & $\begin{array}{l}\text { Patients with } \\
\text { Moderate } \\
\text { AEBA } \\
\mathrm{n}=130\end{array}$ & $\begin{array}{l}\text { Patients with Severe } \\
\text { or Life-Threatening } \\
\qquad \begin{array}{l}\text { AEBA } \\
n=42\end{array}\end{array}$ & $\begin{array}{l}\text { p-value } \\
\quad \text { of } \\
\text { Univariate } \\
\text { Analysis }\end{array}$ & $\begin{array}{l}\text { p-value } \\
\text { of } \\
\text { Multivariate } \\
\text { Analysis }\end{array}$ \\
\hline $\begin{array}{l}\text { Daytime symptoms, n (\%) } \\
\text { Yes } \\
\text { No }\end{array}$ & $\begin{array}{l}124(72.1) \\
48(27.9)\end{array}$ & $\begin{array}{l}88(67.7) \\
42(32.3)\end{array}$ & $\begin{array}{l}36(85.7) \\
6(14.3)\end{array}$ & 0.024 & 0.997 \\
\hline $\begin{array}{l}\text { Nocturnal symptoms, n (\%) } \\
\text { Yes } \\
\text { No }\end{array}$ & $\begin{array}{l}112(65.1) \\
60(34.9)\end{array}$ & $\begin{array}{l}84(64.6) \\
46(35.4)\end{array}$ & $\begin{array}{l}28(66.7) \\
14(33.3)\end{array}$ & 0.808 & - \\
\hline $\begin{array}{l}\text { Rescue SABA use, } \mathbf{n}(\%) \\
\text { Yes } \\
\text { No }\end{array}$ & $\begin{array}{l}122(70.9) \\
50(29.1)\end{array}$ & $\begin{array}{l}88(67.7) \\
42(32.3)\end{array}$ & $\begin{array}{l}34(81.0) \\
8(19.0)\end{array}$ & 0.100 & - \\
\hline $\begin{array}{l}\text { Limitation of activity, } \mathbf{n}(\%) \\
\text { Yes } \\
\text { No }\end{array}$ & $\begin{array}{c}124(72.1) \\
48(27.9)\end{array}$ & $\begin{array}{l}88(67.7) \\
42(32.3)\end{array}$ & $\begin{array}{c}36(85.7) \\
6(14.3)\end{array}$ & 0.024 & 0.997 \\
\hline $\begin{array}{l}\text { Level of asthma control before } \\
\text { exacerbation, } \mathbf{n} \text { (\%) } \\
\text { Well controlled } \\
\text { Partially controlled } \\
\text { Uncontrolled }\end{array}$ & $\begin{array}{l}\text { II (6.4) } \\
44(25.6) \\
\text { II } 17(68.0)\end{array}$ & $\begin{array}{c}8(6.1) \\
34(26.2) \\
88(67.7)\end{array}$ & $\begin{array}{c}3(7.2) \\
10(23.8) \\
29(69.0)\end{array}$ & 0.939 & - \\
\hline $\begin{array}{l}\text { Exacerbations in the previous year, } \mathbf{n}(\%) \\
\text { No } \\
\text { Yes }\end{array}$ & $\begin{array}{l}87(50.6) \\
85(49.4)\end{array}$ & $\begin{array}{l}73(56.2) \\
57(43.8)\end{array}$ & $\begin{array}{l}14(33.3) \\
28(66.7)\end{array}$ & 0.010 & 0.118 \\
\hline $\begin{array}{l}\text { No. of previous admission for asthma, } \\
\text { mean } \pm \text { SD }\end{array}$ & $3.9 \pm 1.4$ & $4.0 \pm 1.4$ & $3.6 \pm 1.3$ & 0.090 & - \\
\hline $\begin{array}{l}\text { No. of previous exacerbations not } \\
\text { requiring hospitalizations/year, mean } \pm \\
\text { SD }\end{array}$ & $1.1 \pm 0.9$ & $1.1 \pm 0.9$ & $1.4 \pm 0.8$ & 0.031 & 0.211 \\
\hline $\begin{array}{l}\text { No. of previous exacerbations requiring } \\
\text { hospitalizations/year, mean } \pm \text { SD }\end{array}$ & $2.0 \pm 1.6$ & $1.8 \pm 1.3$ & $2.8 \pm 1.9$ & $<0.001$ & 0.965 \\
\hline $\begin{array}{l}\text { Previous non-invasive ventilation (NIV), } \\
\text { n (\%) } \\
\text { No } \\
\text { Yes }\end{array}$ & $\begin{array}{l}150(87.2) \\
22(12.8)\end{array}$ & $\begin{array}{c}130(100) \\
0(0)\end{array}$ & $\begin{array}{l}20(47.6) \\
22(52.4)\end{array}$ & $<0.001$ & 0.996 \\
\hline $\begin{array}{l}\text { Previous invasive ventilation, } \mathbf{n}(\%) \\
\text { No } \\
\text { Yes }\end{array}$ & $\begin{array}{l}162(94.2) \\
10(5.8)\end{array}$ & $\begin{array}{l}128(98.5) \\
2(1.5)\end{array}$ & $\begin{array}{l}34(81.0) \\
8(19.0)\end{array}$ & $<0.001$ & 0.998 \\
\hline $\begin{array}{l}\text { Pre-bronchodilator FEV }, \text {, mean } \pm \text { SD }(\% \\
\text { predicted) }\end{array}$ & $61.9 \pm 16.1$ & $64.5 \pm 15.6$ & $53.6 \pm 14.9$ & $<0.001$ & 0.108 \\
\hline $\begin{array}{l}\text { Baseline blood eosinophil count, mean } \pm \\
\text { SD (cell/ } \mu \mathrm{L})\end{array}$ & $238.3 \pm 233.8$ & $196.2 \pm 217.4$ & $368.6 \pm 237.4$ & $<0.001$ & $\begin{array}{l}0.001 \\
\text { OR: } 1.01 \\
95 \% \mathrm{Cl}: \\
1.00-1.01\end{array}$ \\
\hline
\end{tabular}

(Continued) 
Table 2 (Continued).

\begin{tabular}{|c|c|c|c|c|c|}
\hline Characteristics & $\begin{array}{c}\text { Total } \\
\text { Patients } \\
\mathbf{N}=172\end{array}$ & $\begin{array}{l}\text { Patients with } \\
\text { Moderate } \\
\text { AEBA } \\
n=130\end{array}$ & $\begin{array}{l}\text { Patients with Severe } \\
\text { or Life-Threatening } \\
\text { AEBA } \\
n=42\end{array}$ & $\begin{array}{l}\text { p-value } \\
\text { of } \\
\text { Univariate } \\
\text { Analysis }\end{array}$ & $\begin{array}{l}\text { p-value } \\
\text { of } \\
\text { Multivariate } \\
\text { Analysis }\end{array}$ \\
\hline $\begin{array}{l}\text { Treatment prescribed prior to } \\
\text { exacerbation, } n(\%)\end{array}$ & & & & \multirow[t]{6}{*}{$0.003 *$} & \multirow[t]{6}{*}{0.668} \\
\hline $\begin{array}{l}\text { GINA Step I: } \\
\text { As-needed low dose inhaled corticosteroids } \\
\text { (ICS)-formoterol }\end{array}$ & $2(1.2)$ & $2(1.5)$ & $0(0)$ & & \\
\hline $\begin{array}{l}\text { GINA Step 2: } \\
\text { Low dose inhaled ICS or as-needed low dose } \\
\text { ICS-formoterol or } \\
\text { Leukotriene receptor antagonist (LRTA) only }\end{array}$ & $70(40.7)$ & $59(45.4)$ & II (26.2) & & \\
\hline $\begin{array}{l}\text { GINA Step 3: } \\
\text { Low dose ICS-long acting beta } 2 \text {-agonist (LABA) } \\
\text { or medium dose ICS or low dose ICS with } \\
\text { LRTA }\end{array}$ & $2(1.2)$ & $2(1.5)$ & $0(0)$ & & \\
\hline $\begin{array}{l}\text { GINA Step 4: } \\
\text { Medium dose ICS-LABA or } \\
\text { High dose ICS with Tiotropium and LRTA }\end{array}$ & $77(44.8)$ & $58(44.6)$ & $19(45.2)$ & & \\
\hline $\begin{array}{l}\text { GINA Step 5: } \\
\text { High dose ICS-LABA or } \\
\text { add on low dose OCS }\end{array}$ & $2 \mid(12.2)$ & $9(6.9)$ & $12(28.6)$ & & \\
\hline \multicolumn{6}{|l|}{ Adherence to treatment, $n$ (\%) } \\
\hline $\begin{array}{l}\text { Yes } \\
\text { No }\end{array}$ & $\begin{array}{l}108(62.8) \\
64(37.2)\end{array}$ & $\begin{array}{l}75(56.7) \\
55(43.3)\end{array}$ & $\begin{array}{l}34(81.0) \\
8(19.0)\end{array}$ & 0.007 & $\begin{array}{c}0.036 \\
\text { OR: } 6.06 \\
95 \% \text { Cl: I.I3 } \\
-32.49\end{array}$ \\
\hline \multicolumn{6}{|l|}{ Reported main triggers, n (\%) } \\
\hline Upper respiratory tract infection & $62(36.0)$ & $52(40.0)$ & $10(23.8)$ & 0.006 & 0.257 \\
\hline Haze & $60(34.9)$ & $34(26.2)$ & $26(61.9)$ & & 0.195 \\
\hline Reduction in controller treatment & $50(29.1)$ & $44(33.8)$ & $6(14.3)$ & & \\
\hline
\end{tabular}

Note: *Comparison between patients in GINA Step 5 versus those in Steps I-4. Abbreviation: AEBA, acute exacerbation of bronchial asthma.

have previous admissions requiring non-invasive ventilation $(p<0.001)$ and invasive ventilation $(\mathrm{p}<0.001)$.

Pooling the pre-bronchodilator spirometry results of all 172 patients together, the patients had a mean $\mathrm{FEV}_{1}$ of $61.9 \%$ predicted and a mean baseline blood eosinophil count of 238.3 cells $/ \mu \mathrm{L}$. Patients who presented with severe or life-threatening exacerbations had a significantly lower mean $\mathrm{FEV}_{1}$ of $53.6 \%$ predicted at baseline $(p<0.001)$ and a higher mean baseline eosinophil count of 368.6 cells $/ \mu \mathrm{L}(\mathrm{p}<0.001)$.
A significantly higher percentage of patients with severe or life-threatening exacerbations were on the highest GINA Step of treatment, namely Step 5 compared to those with moderate exacerbations $(\mathrm{p}=0.003)$. More than a third (37.2\%) of patients who were admitted with acute asthma had not adhered to daily controller medications despite being prescribed an inhaled corticosteroid (ICS) previously. However, non-adherence was significantly more common in patients with moderate exacerbations $(p=0.007)$. The most common reasons given for non- 
adherence were not seeing the need to take the medication (45\%), forgetting $(25 \%)$ and fear of long-term dependence to an inhaler $(15 \%)$. Other reasons given included feeling embarrassed about using their inhaler and fear of using an ICS.

Reported triggers were mainly upper respiratory tract infections $(36.0 \%)$, haze $(34.9 \%)$ or a self-imposed reduction in controller treatment $(29.1 \%)$. Patients who presented with moderate exacerbations reported upper respiratory tract infections as the most common trigger, whereas patients who had severe or life-threatening exacerbations cited haze as the most common trigger, and the differences were statistically significant $(\mathrm{p}=0.006)$.

Characteristics found to be statistically significant on univariate analysis were subsequently included in the multivariate analysis. A high baseline blood eosinophil count was found to be an independent predictor of a severe or life-threatening asthma exacerbation (odds ratio: 1.01, 95\% confidence interval: $1.00-1.01, \mathrm{p}=0.001)$. Nonadherence to treatment was found to be significantly more among patients with moderate exacerbations (odds ratio: $6.06,95 \%$ confidence interval: 1.13-32.49, $\mathrm{p}=0.036)$.

\section{Management of Asthma Exacerbation}

Table 3 highlights important aspects of management upon presentation to the emergency department of both hospitals. First peak expiratory flow (PEF) was recorded as part of initial assessment in $77.9 \%$ of the cases among patients who were not intubated and were not confused upon presentation. Supplemental oxygen was administered to all patients with severe or life-threatening exacerbations. Intravenous corticosteroids were given to all patients admitted at both centres within 1 hour of arrival at the emergency department.

The length of hospitalization was variable with a median of 4 days. For patients not admitted to the ICU, the longest stay was 10 days. A significant proportion of patients $(33.7 \%)$ were reviewed by a member of the critical care team. Twenty-two patients (11.6\%) were admitted to the ICU and five patients required tracheal intubation and mechanical ventilation. Of patients admitted to the ICU, all received intravenous magnesium sulphate. The median length of stay in the ICU was 4 days, the longest was 10 days.
Table 3 Clinical Data During Assessment of Exacerbation and Management

\begin{tabular}{|c|c|}
\hline & $\begin{array}{l}\text { Total Patients, } \\
\qquad \mathrm{N}=172\end{array}$ \\
\hline $\begin{array}{l}\text { Oxygen saturation at presentation, mean } \\
\pm \text { SD (\%) }\end{array}$ & $94.2 \pm 3.7$ \\
\hline \multicolumn{2}{|l|}{$\begin{array}{l}\text { PEFR measurement on initial assessment, } \\
\text { n (\%) }\end{array}$} \\
\hline Yes & I34 (77.9) \\
\hline No & $38(22.1)$ \\
\hline \multicolumn{2}{|l|}{$\begin{array}{l}\text { Arterial blood gas analysis performed, } \\
\mathrm{n}(\%)\end{array}$} \\
\hline Yes & $102(59.3)$ \\
\hline No & $70(40.7)$ \\
\hline \multicolumn{2}{|l|}{ Presence of hypercapnia, n (\%) } \\
\hline Yes & $40(23.3)$ \\
\hline No & I 32 (76.7) \\
\hline \multicolumn{2}{|l|}{$\begin{array}{l}\text { Prescription of systemic corticosteroids, } \\
\text { n (\%) }\end{array}$} \\
\hline Yes & $172(100)$ \\
\hline No & 0 \\
\hline \multicolumn{2}{|l|}{$\begin{array}{l}\text { Administration of regular nebulised } \\
\text { bronchodilators, } \mathbf{n}(\%)\end{array}$} \\
\hline Yes & $172(100)$ \\
\hline No & 0 \\
\hline $\begin{array}{l}\text { Length of hospital stay, median and range } \\
\text { (days) }\end{array}$ & $4(3-10)$ \\
\hline \multicolumn{2}{|l|}{ Critical care team review, $n$ (\%) } \\
\hline Yes & $58(33.7)$ \\
\hline No & II4 (66.3) \\
\hline \multicolumn{2}{|l|}{$\begin{array}{l}\text { Admission to intensive care unit (ICU), } \\
\text { n (\%) }\end{array}$} \\
\hline Yes & $22(11.6)$ \\
\hline No & I50 (88.4) \\
\hline $\begin{array}{l}\text { Of those admitted to ICU, } \mathbf{n =} \mathbf{2 2} \\
\text { Invasive mechanical ventilation, } \mathrm{n}(\%) \\
\text { No invasive mechanical ventilation, } \mathrm{n}(\%)\end{array}$ & $\begin{array}{l}5(25.0) \\
17(75.0)\end{array}$ \\
\hline $\begin{array}{l}\text { Length of ICU stay, median and range } \\
\text { (days) }\end{array}$ & $4(3-10)$ \\
\hline $\begin{array}{l}\text { Total hospital stay for ICU admission, } \\
\text { median and range (days) }\end{array}$ & $8(6-16)$ \\
\hline
\end{tabular}

\section{Discharge from Hospital}

Table 4 shows the discharge plans of patients who were admitted for asthma exacerbations. Pre-discharge PEFR was performed in all $(100 \%)$ patients at both centres. All 
Table 4 Discharge Plans

\begin{tabular}{|l|c|}
\hline & No. of Patients, N = I 72 \\
\hline $\begin{array}{l}\text { PEFR before discharge, } \mathbf{n} \text { (\%) } \\
\text { Yes }\end{array}$ & $172(100)$ \\
No & $0(0)$ \\
\hline $\begin{array}{l}\text { Discharged on ICS therapy, } \\
\mathbf{n} \text { (\%) } \\
\text { Yes }\end{array}$ & $172(100)$ \\
No & $0(0)$ \\
\hline $\begin{array}{l}\text { Inhaler technique review, } \mathbf{n}(\%) \\
\text { Yes }\end{array}$ & $120(69.8)$ \\
No & $52(30.2)$ \\
\hline Written personal asthma & \\
action plan, $\mathbf{n}$ (\%) & \\
Yes & $43(25)$ \\
No & $129(75)$ \\
\hline
\end{tabular}

Abbreviation: PEFR, peak expiratory flow rate.

newly diagnosed asthmatics were discharged on ICS therapy, as recommended by GINA. Of those non-adherent to previously prescribed treatment, the reasons for poor adherence were discussed and addressed. Seventy-eight percent of the patients were sent home on a short course of oral corticosteroids. The remaining $22 \%$ completed 5 days of systemic corticosteroids during hospitalisation.

Prior to discharge, inhaler technique was reviewed in $69.8 \%$ of cases. Amongst patients who were on a pressurized metered-dose inhalers (pMDI) and had their inhaler technique checked, only $58 \%$ had good pMDI technique. Failure to initiate the breath before actuating the pMDI inhaler was seen in $25 \%$ of the patients, while failure to inhale slowly and deeply was a major problem with pMDI usage seen in $40 \%$ of the patients. The remaining mistakes included not shaking the inhaler prior to use (10\%), not exhaling fully prior to inhaling (10\%), failure to use one puff at a time $(10 \%)$ and failure to hold the breath for 10 seconds (5\%). Reassuringly, the majority of patients improved either by education or by supplementation with a spacer prior to discharge and only $5 \%$ required a change to a dry powder inhaler.

A written personal asthma action plan was only provided to $25 \%$ of the patients. Most were verbally communicated and triggers and exacerbating factors discussed without actual provision of a written action plan. A clinic review appointment was scheduled in all patients at both centres with a mean follow-up appointment of 2 weeks after discharge. There were no deaths recorded for acute asthma during the study period. However, only $69.8 \%$ of the patients returned for their follow-up appointments.

\section{Discussion}

In Southeast Asia, asthma is among the commonest noncommunicable diseases. ${ }^{5}$ More than $73 \%$ of outpatient health clinic visits are for respiratory symptoms, among which many are asthma-related. ${ }^{16}$ According to the National Health and Morbidity Survey in 2011, the national prevalence of self-reported, doctor-diagnosed asthma in Malaysia was $6.4 \% .{ }^{17}$ It is estimated that there are about 1.6 to 2 million people with asthma in Malaysia. ${ }^{12}$ Of the asthma cases, $9.9 \%$ and $2.7 \%$ were of moderate and severe grades, respectively. ${ }^{12}$ Each acute asthma attack lasted for about 3.7-4.6 days. This translates into loss of productivity and quality of life for 2.4 days per episode. $^{12}$

Many countries have formulated and published their own asthma management guidelines to improve asthma care. Nevertheless, evidence from countries such as Sweden, Australia, Pakistan, Egypt and Taiwan indicate that clinical practice guidelines are not necessarily adhered to despite their availability. ${ }^{18-22}$ Despite the availability of treatment guidelines such as that by the Global Initiative for Asthma (GINA), the incidence of asthma control in the real-world has been reported to be considerably lower than the levels reported in many randomised controlled trials. $^{23,24}$

To our knowledge, this is the first real-world study in Southeast Asia focusing on the quality and organisation of acute asthma management in tertiary care centres. There are only two regional studies to date, namely the Asthma Insights and Reality in Asia-Pacific (AIRIAP) survey in 2000 and the Asthma Insight and Management (AIM) study from 2009 to 2011.

The AIRIAP study is the only regional survey back in the year 2000 which reported asthma severity and management in urban centres of eight areas of the Asia-Pacific regions. ${ }^{25,26}$ The survey highlighted that only $13.6 \%$ of the respondents were using ICS as a controller medication despite almost half of the respondents meeting the criteria for persistent asthma. ${ }^{25}$ In comparison, a higher proportion of patients admitted for an exacerbation were adherent to using ICS as a controller medication in our study (62.8\%). This could perhaps be related to better knowledge and conviction in using ICS as a controller medication in Southeast Asia since then. 
The Asthma Insight and Management (AIM) study from 2009 to 2011 also reported a lack of knowledge and conviction for treatment recommendations across the Asia-Pacific region in patients having persistent asthma. ${ }^{27}$ Among 413 Malaysians included in the AIM study, 22\% reported daytime symptoms, $24 \%$ reported night-time symptoms, and $42 \%$ required an emergency visit for treatment of asthma exacerbations within the previous year. ${ }^{27}$ In contrast to our study of 172 Malaysians, $72 \%$ reported daytime symptoms, $65 \%$ reported night-time symptoms, and $50 \%$ required an emergency visit for treatment of asthma exacerbations within the previous year with more than half of these requiring hospitalization. This suggests that the asthma patients in our study had more uncontrolled asthma. A history of asthma exacerbations is a risk factor for future exacerbation. ${ }^{1}$ This was also reflected in our study where patients with severe and lifethreatening exacerbations had more hospitalizations in a year with an average of 2.8 admissions and were also more likely to have previous admissions requiring noninvasive and invasive ventilation.

One of the main findings from our study is the level of GINA-defined asthma control remained low with only $6.4 \%$ of the patients deemed to have good control while asthma was uncontrolled in $68 \%$ of the patients. The incidence of symptoms and acute exacerbations were high, with $49.4 \%$ experiencing an exacerbation in the previous year. Surprisingly, approximately $75 \%$ of our patients considered their asthma to be controlled despite many of them having had a history of acute exacerbations in the previous year. The observed incidences of uncontrolled asthma and symptoms were slightly higher than those reported globally (51\%-57\%), suggesting more work needs to be done to achieve better asthma control in patients in the region. ${ }^{10,28,29}$ In a survey involving 8,000 European asthma patients, $45 \%$ were found to have uncontrolled asthma despite more than $80 \%$ considering their asthma to be controlled. ${ }^{30}$ Herein lies the major reason, where many patients regard their asthma as controlled and not serious despite experiencing symptoms and exacerbations requiring oral steroids, emergency department visits or hospitalizations. Most patients did not recognise symptoms as being indicators of poor control, suggesting a disconnect between patients' perceptions of control and guideline-defined control. ${ }^{30}$ Many patients may overestimate their symptoms control and underestimate the severity of their asthma, indicating that they tolerate symptoms and lifestyle limitations. For patients, asthma control may be most easily understood as managing exacerbation risk, rather than as achieving a predefined threshold of symptoms control. ${ }^{30}$ It is therefore important to understand, and tailor-specific treatment to accommodate different patient attitudes towards their condition and to their specific needs to improve real-world outcomes.

Another interesting finding of the study is the presence of haze during the study period which was a trigger in up to a quarter of the exacerbations. The haze was a transboundary increase in air pollution caused mainly by forest and peatland fire affecting countries in Southeast Asia that was particularly severe in the months of August and September 2019. ${ }^{31}$ It is comprised of high concentration of particulate matter, predominantly less than 2.5 microns in size (PM2.5) that is sufficiently small enough to penetrate deep into the respiratory tract. $^{32}$ Approximately $34.9 \%$ of our patients developed exacerbations triggered by the haze with more than half of the asthma admissions recorded in the months of August and September 2019. Majority of patients (61.9\%) who presented during this period with a severe or life-threatening exacerbation cited the haze as the most common trigger. Moreover, increases in hospital admissions of respiratory diseases have also been documented in Malaysia during the Southeast Asia haze in 2014 and 2015. ${ }^{33}$ Our neighbour country, Singapore also documented a $20 \%$ increase in hospitalisations for asthma during one of the haze periods. ${ }^{34}$ The Global Burden of Disease collaboration in 2017 reported that ambient indoor and outdoor air pollution cause a far greater share of chronic respiratory disease-attributable disability in Southeast Asia than they do in other parts of the world. ${ }^{35}$ Different strategies to minimise exposure to these well-known risk factors remain underutilised. ${ }^{35}$ Given the severity of exacerbations caused by haze as seen in our study and the high mortality rates due to chronic respiratory diseases in South Asia, increased attention and resources should be allocated to address and minimise these risk factors. ${ }^{35}$

When assessing the treatment step that patients were on prior to their exacerbations, we found that only $1.5 \%$ of the patients were on Step 1 treatment of the GINA 2019 guidelines suggesting a bigger pool of patients who were deemed to have persistent asthma requiring daily ICS, despite $37 \%$ of them not being adherent to them, with almost half of them not seeing the need to use ICS and preferring to use as-needed short-acting beta 2 -agonist (SABA) instead. This finding is in keeping with the reasons behind the change in Step 1 of the GINA 2019 
guidelines with an emphasis made on the role of ICS in preventing asthma exacerbations even in patients with mild asthma, moving away from as needed SABA to as needed low-dose ICS-formoterol. Frequent reliever inhaler use was notable, with more than $70 \%$ of the patients having to use their SABA inhaler three or more times a week. This may reflect high levels of uncontrolled asthma, but is also a reflection of over-reliance on rescue medication, suggesting that patients do not recognize reliever use as a sign of deteriorating asthma and that their treatment may require adjustment. ${ }^{10}$ Moreover, the proportion of patients with uncontrolled asthma was high across all treatment levels, which may indicate under-use, inappropriate use, or under-prescription of therapies, thus highlighting the need for close supervision, guidance and empowerment of patients to achieve better selfmanagement of their asthma.

Another important finding from this study is a higher percentage of patients who had severe or life-threatening exacerbations were on GINA Step 5 treatment compared to those with moderate exacerbations. Patients with severe or life-threatening exacerbations also had a significantly lower mean percent predicted $\mathrm{FEV}_{1}$ and a higher baseline blood eosinophil count. This was consistent with a UK cohort study of 130,000 patients with asthma, where a clear count-response relation exists between blood eosinophil count and exacerbation rates and asthma-related outcomes. $^{36}$ Exacerbation rates increased progressively with nine ascending categories of blood eosinophil counts as compared with a reference category of 200 cells per $\mu \mathrm{L}$ or less. ${ }^{36}$ This finding was also observed in two separate randomised controlled trial of patients with severe eosinophilic asthma, where a progressive increase in risk of exacerbation was found with increasing baseline blood eosinophils. $^{37,38}$ Our data suggest that patients with high blood eosinophil count are potentially at greater risk of future severe or life-threatening exacerbations and should be counselled, treated and monitored accordingly.

This study also shows non-adherence to treatment remains high in our patients $(37.2 \%)$, although they were significantly more among patients with moderate exacerbations. This is consistent with the findings of the AIRIAP study in the year $2000 .^{23}$ Patients who presented with a severe or life-threatening exacerbation were perhaps more aware of the importance of medication adherence, suggesting other factors such as blood eosinophil counts and treatment adequacy play a greater role in the severity of an exacerbation. The most common reasons given for non-adherence were not seeing the need to take it $(45 \%)$, forgetting (25\%) and fear of long-term dependence to an inhaler $(15 \%)$. Non-adherence has been traditionally found to be associated with suboptimal asthma control. ${ }^{1}$ This highlights the importance of intervention with education and a clear asthma management plan on discharge emphasising the importance of regular ICS use.

Another concern is inhaler technique was assessed in only $69.8 \%$ of the cases with the remaining not having their inhalers checked despite the exacerbation being severe enough to warrant hospitalisation. Of those checked for inhaler technique, only $58 \%$ were found to have good inhaler technique when using a pMDI. The mistakes were mainly found in the failure to initiate breathing before actuating the inhaler and failure to inhale slowly and deeply, as observed in $25 \%$ and $40 \%$ of the patients, respectively. The other mistakes were not shaking the inhaler prior to use, not exhaling fully prior to inhaling, failure to use one puff at a time and failure to hold the breath for 10 seconds. Studies have demonstrated that instruction by health care providers on correct metereddose inhaler use is a modifiable factor for reducing incorrect inhaler technique. ${ }^{39}$

Only $25 \%$ of the patients were provided with a written asthma action plan upon discharge. These shortcomings of not reviewing the inhaler technique and educating through a written asthma action plan are common globally and need to be addressed to prevent readmissions, fatality and wastage of medications. There is also a need to assess patients' risk and inhaler technique, and to ensure that patients are prescribed, and take, appropriate medications, in order to improve asthma control. ${ }^{30}$

A clinic review appointment was scheduled in all patients at both centres at a mean duration of 2 weeks upon discharge. GINA recommends a follow-up appointment within 2 days of discharge with the patient's usual health care provider to ensure continuity of treatment. Unfortunately, this is very difficult to achieve within the context of many Southeast Asian healthcare system. Malaysia differs from other countries in the Southeast Asian region such as Indonesia and the Philippines in that it does not have an administratively decentralized public sector health care system. ${ }^{40}$ Primary health care in urban areas are partly provided by the private sector. ${ }^{40}$ The scheduling of follow-up visits cannot reach guidelines recommendation due to inadequate capacity in the public primary care system while private primary care can be costly. More efforts need to be placed on 
decongesting specialist respiratory clinics at the tertiary care level to allow more severe cases to be followed up within a shorter timeframe.

There were limitations in this study. Firstly, only two tertiary centres were selected to be part of this study, which may not be fully representative of asthma care in the region. Secondly, this study also assessed documentation of care as a proxy for actual care, which could have led to an over-, or underestimation of the quality of care actually offered. Thirdly, data were collected over a 6-month period, thus limiting the understanding of the way patients adapt to therapy longitudinally. Fourthly, despite capturing data on previous admissions for acute exacerbations of asthma, only the first exacerbation which fell within the study period was analysed and as such information on symptom control and benefits of treatment intervention were limited. Lastly, data on types of allergic responses and Immunoglobulin E were limited as they were not routinely performed and were confined to a few with severe allergic asthma who could afford to pay for testing.

\section{Conclusion}

Despite availability of practice guidelines and recommended treatment, asthma control in Southeast Asia remains poor. Symptoms and exacerbations are common across all treatment levels and there remains a marked discrepancy between patient-perceived and guidelinedefined asthma control. There is considerable room for improvement in acute asthma care in Southeast Asia. The study provides useful and important information for health care planners for policy implementation as well as evaluation of health care services regionally. As a significant proportion of patients with uncontrolled asthma are not adherent with their controller medications, further education to increase awareness on the dangers of uncontrolled asthma is warranted. There is a clear need to assess patients' asthma control and inhaler technique to ensure appropriate treatments are prescribed and adhered to.

\section{Data Sharing Statement}

The datasets used and/or analysed during the current study are available from the corresponding author on reasonable request.

\section{Ethics Approval and Consent to Participate}

The study was granted approval and ethical clearance by the medical ethics review board of University of Malaya Medical Centre (MECID No: 2018725-6524).

\section{Consent for Publication}

Patients recruited for the study consented for publication without any identifying information.

\section{Author Contributions}

All authors contributed to data analysis, drafting or revising the article, have agreed on the journal to which the article will be submitted, gave final approval of the version to be published, and agree to be accountable for all aspects of the work.

\section{Funding}

This research is partially supported by Asthma Malaysia.

\section{Disclosure}

The authors report no conflicts of interest in this work.

\section{References}

1. Global Initiative for Asthma (GINA). Global strategy for asthma management and prevention, 2019. Available from: https:// ginasthma.org/wp-content/uploads/2019/06/GINA-2019-main-reportJune-2019-wms.pdf. Accessed May 14, 2021.

2. Asthma 2020. Available from: https://www.who.int/news-room /q-a-detail/asthma. Accessed May 14, 2021.

3. GBD 2015 Chronic Respiratory Disease Collaborators. Global, regional, and national deaths, prevalence, disability-adjusted life years, and years lived with disability for chronic obstructive pulmonary disease and asthma, 1990-2015: a systematic analysis for the Global Burden of Disease Study 2015. Lancet Respir Med. 2017;5:691-706.

4. World Health Organization (WHO). Global surveillance, prevention, and control of chronic respiratory diseases: a comprehensive approach, 2007. Available from: https://www.who.int/gard/publica tions/GARD\%20Book\%202007.pdf. Accessed May 14, 2021.

5. Bahari MB, Mohd Nur M, Rahman FAB. A knowledge of asthma in school children: a survey among primary school teachers. Singapore Med J. 2003;44:131-135.

6. Quirce S, Heffler E, Nenasheva N, et al. Revisiting late-onset asthma: clinical characteristics and association with allergy. J Asthma Allergy. 2020;13:743-752.

7. Dharmage SC, Perret JL, Custovic A. Epidemiology of asthma in children and adults. Front Pediatr. 2019;7:246.

8. Miranda C, Busacker A, Balzar S, et al. Distinguishing severe asthma phenotypes: role of age at onset and eosinophilic inflammation. J Allergy Clin Immune. 2004;113:101-108.

9. Demoly P, Annunziata K, Gubba E, et al. Repeated cross-sectional survey of patient-reported asthma control in Europe in the past 5 years. Eur Respir Rev. 2012;21:66-74.

10. Patridge MR, van der Molen T, Myrseth SE, et al. Attitudes and actions of asthma patients on regular maintenance therapy: the INSPIRE study. BMC Pulm Med. 2006;6:13.

11. Demoly P, Gueron B, Annunziata K, et al. Update on asthma control in five European countries: results of a 2008 survey. Eur Respir Rev. 2010;19:150-157.

12. Bakri R, Mohd Said N, Mohan J, et al. Ministry of Health. Malaysia: National Health and Morbidity Survey; 1999.

13. Radhakrishna N, Tay TR, Hore-Lacy F, et al. Profile of difficult to treat asthma patients referred for systematic assessment. Respir Med. 2016;117:166-173. 
14. Marseglia GL, Caimmi S, Marseglia A, et al. Rhinosinusitis and asthma. Int J Immunopathol Pharmacol. 2010;23:29-31.

15. Adult tobacco use information. National Center for Health Statistics, Centers for Disease Control and Prevention (CDC), 2017. https:// www.cdc.gov/nchs/nhis/tobacco/tobacco_glossary.htm. Accessed May 14, 2021.

16. Rozlan I. The study on asthma admissions in Malaysia. Disease Control Division (NCD), Ministry of Health Malaysia. 2002;1:10-17.

17. Ministry of Health, Malaysia. National health and morbidity survey: healthcare demand and out-of-pocket health expenditure, 2011. Available from: http://iku.moh.gov.my/images/IKU/Document/ REPORT/NHMS2011-VolumeIII.pdf. Accessed May 14, 2021.

18. Jonsson M, Egmar AC, Kiessling A, et al. Adherence to national guidelines for children with asthma at primary health centres in Sweden: potential for improvement. PrimCare Respir J. 2012;21:276-282.

19. Barton C, Proudfoot J, Amoroso C, et al. Management of asthma in Australian general practice: care is still not in line with clinical practice guidelines. Prim Care Respir J. 2009;18:100-105.

20. Hussain SF, Zahid S, Khan JA, et al. Asthma management by general practitioners in Pakistan. Int J Tuberc Lung Dis. 2004;8:414-417.

21. Salama AA, Mohammed AA. El Okda el SE, et al. Qual Care Egypt Asthmatic Child. 2010;21(36):33.

22. Yeh KW, Chiang LC, Chen SH, et al. Survey of the clinical practice of physicians in the management of asthma in Taiwan. Asian Pac J Allergy Immunol. 2006;24:1-8.

23. Pedersen S. From asthma severity to control: a shift in clinical practice. Prim Care Respir J. 2010;19:3-9.

24. Bateman ED, Boushey HA, Bousquet J, et al. Can guideline-defined asthma control be achieved? The Gaining Optimal Asthma ControL study. Am J Respir Crit Care Med. 2004;170:836-844.

25. Lai CKW, Guia TS, Kim YY, et al. Asthma control in the Asia-Pacific region: the asthma insights and reality in Asia-Pacific study. J Allergy Clin Immunol. 2003;111:263-268.

26. Zainudin BM, Lai CKW, Soriano JB, Jia-Horng W, Guia TS. Asthma Insights and Reality in Asia-Pacific (AIRIAP) Steering Committee. Asthma Contro Adults Asia Pac Respirol. 2005;10:579-586.

27. Nathan RA, Thompson PJ, Price D, et al. Taking aim at asthma around the world: global results of the asthma insight and management survey in the Asia Pacific Region, Latin America, Europe, Canada, and the United States. $J$ Allergy Clin Immunol. 2015;3:734-742.

28. Rabe KF, Adachi M, Lai CK, et al. Worldwide severity and control of asthma in children and adults: the global asthma insights and reality surveys. J Allergy Clin Immunol. 2004;114:40-47.
29. Bellamy D, Harris T. Poor perceptions and expectations of asthma control: results of the International Control of Asthma Symptoms (ICAS) survey of patients and general practitioners. Prim Care Respir J. 2005;14:252-258.

30. Price D, Fletcher M, van der Molen T. Asthma control and management in 8,000 European patients: the REcognise Asthma and Link to Symptoms and Experience (REALISE) survey. Npj Prim Care Resp Med. 2014;24:14009.

31. Cheong KH, Ngiam NJ, Morgan GG, et al. Acute health impacts of the Southeast Asian transboundary haze problem - a review. Int J Environ Res Public Health. 2019;16:3286.

32. Pavagadhi S, Betha R, Venkatesan S, Balasubramaniam R, Hande MP. Physicochemical and toxicological characteristics of urban aerosols during a recent Indonesian biomass burning episode. Environ Sci Pollut Res. 2013;20:2569.

33. Ming CR, Ban AYL, Abdul Hamid MF, Latif TM, Mohammad N, Hassan T. Annual Southeast Asia haze increases respiratory admissions: a 2-year large single institution experience. Respirology. 2018;23:914-920.

34. Chew FT, Ooi BC, Hui JK, Saharom R, Goh DY, Lee BW. Singapore's haze and acute asthma in children. Lancet. 1995;346:1427.

35. GBD Chronic Respiratory Disease Collaborators. Prevalence and attributable health burden of chronic respiratory diseases, 1990-2017: a systematic analysis for the Global Burden of Disease Study 2017. Lancet Respir Med. 2020;8:585-596.

36. Price DB, Rigazio A, Campbell JD, et al. Blood eosinophil count and prospective annual asthma disease burden: a UK cohort study. Lancet Respir Med. 2015;3:849-858.

37. Pavord ID, Korn S, Howarth P, et al. Mepolizumab for severe eosinophilic asthma (DREAM): a multicentre, double-blind, placebo-controlled trial. Lancet. 2012;380:651-659.

38. Wenzel S, Ford L, Pearlman D, et al. Dupilumab in persistent asthma with elevated eosinophil levels. N Eng J Med. 2013;368:2455-2466.

39. Melani AS, Bonavia M, Cilenti V, et al. Inhaler mishandling remains common in real life and is associated with reduced disease control. Respir Med. 2011;105:930-938.

40. World Health Organization. Malaysian health system review. Health Syst Transit. 2012;2:1.

\section{Publish your work in this journal}

The Journal of Asthma and Allergy is an international, peer-reviewed open-access journal publishing original research, reports, editorials and commentaries on the following topics: Asthma; Pulmonary physiology; Asthma related clinical health; Clinical immunology and the immunological basis of disease; Pharmacological interventions and new therapies. The manuscript management system is completely online and includes a very quick and fair peer-review system, which is all easy to use. Visit http://www.dovepress.com/testimonials.php to read real quotes from published authors. 